\title{
UM ESTUDO EMPÍRICO SOBRE A IMPORTÂNCIA DO CÓDIGO DE ÉTICA PROFISSIONAL PARA O CONTABILISTA
}

\author{
AN EMPIRICAL STUDY ON THE IMPORTANCE OF \\ PROFESSIONAL CODE OF ETHICS FOR ACCOUNTANTS
}

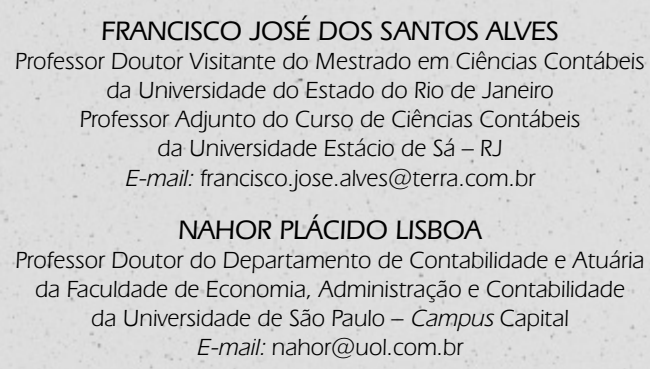

FRANCISCO JOSÉ DOS SANTOS ALVES

Professor Doutor Visitante do Mestrado em Ciências Contábeis

da Universidade dó Estado do Rio de Janeiro

Professor Adjunto do Curso de Ciências Contábeis

da Universidade Estácio de Sá - RJ

E-mail: francisco.jose.alves@terra.com.br

NAHOR PLÁCIDO LISBOA

Professor Doutor do Departamento de Contabilidade e Atuária da Faculdade de Economia, Administração e Contabilidade da Universidade de São Paulo - Campus Capital E-mail:nahor@uol.com.br

\author{
ELIONOR FARAH JREIGE WEFFORT \\ Professora Doutora do Mestrado em Ciências Contábeis \\ da Fundação Escola de Comércio Álvares Penteado - SP \\ E-mail::eweffort@directnet.com.br \\ MARIA THEREZA POMPA ANTUNES \\ Professora Doutora do Curso de Ciências Contábeis \\ do Centro de Ciências Sociais e Aplicadas. \\ da Universidade Presbiteriana Mackenzie - SP \\ E-mail: mariathereza@mackenzie.com.br
}

\section{RESUMO}

Este estudo trata de uma pesquisa empírica e de natureza quantitativa, com o objetivo de investigar a influência do Código de Ética sobre o processo decisório ético do profissional de Contabilidade. O questionário foi aplicado por meio da Internet e respondido por 2262 contadores e técnicos em Contabilidade com registro ativo no Conselho Regional de Contabilidade de 4 Estados brasileiros. Seus resultados, obtidos por meio da regressão logística multivariada, sugerem, entre outros aspectos, a existência de uma contradição: a maioria dos profissionais considera o Código de Ética Profissional do Contabilista importante como guia de conduta, mas apenas uma minoria se predispõe a cumprir algumas ou todas as normas emanadas do Conselho Federal de Contabilidade.

Palavras-chave: Ética profissional; Código de ética; Contabilidade; Ética.

\section{ABSTRACT}

This study aims to investigate the influence of the Code of Ethics (CEPC) in the ethical decision-making process of Brazilian accountants. It adopts a descriptive research approach and a quantitative method for analysis of data. Questionnaires were conducted via Internet and returned by 2262 accountants and accountant technicians, certified and chartered by the Regional Council of Accounting in the states of Rio de Janeiro, São Paulo, Minas Gerais and Rio Grande do Sul. The results obtained show, among others, a contradiction: approximately 73\% of professionals polled totally agree with the statement claiming that the Code is important as a guide of conduct; however, only $44 \%$ are willing to comply with the guidelines established by the Federal Council of Accounting.

Keywords: Professional Ethics; Ethics Code; Accountants; Ethics. 


\section{INTRODUC̣ÃO}

Ao longo dos últimos anos, constata-se o crescimento das discussões sobre a conduta ética dos indivíduos em diversos campos da atividade humana, tais como na política e no campo profissional. Na área de negócios, mais especificamente, escândalos recentes nos EUA - Enron, WorldCom, Adelphia, Tyco International e Quest - levaram ao desenvolvimento da lei Sarbanes-Oxley (2002). Essa lei determina a divulgação de informações a respeito da existência, ou não, de um Código de Ética a ser adotado pelos seus principais executivos, obrigando-os a acatar $e$ praticar suas determinações, caso exista. Embora não seja uma norma exigida para todas as empresas, torna-se legalmente requerida para empresas com ações em Bolsa de Valores norte-americanas.

No Brasil, ainda que não existam normas que obriguem a constituição de Códigos de Ética empresariais, em algumas profissões, como: Contabilidade, Administração ou Direito, o exercício da atividade profissional, seja como autônomo ou assalariado, é regido, entre outras normas, por um Código de Ética Profissional emanado do órgão de classe.

A função dessas entidades é a de proteger a sociedade de maus profissionais que exercem funções de relevante interesse público. Por esse motivo, fiscalizam as atividades de seus membros por meio de um Código de Ética profissional.

Esses códigos contêm os padrões morais ${ }^{1}$ que os profissionais de uma determinada classe devem aceitar e observar. Além disso, têm como objetivo regular as relações entre os membros dessa categoria, bem como entre ela e a sociedade, de maneira impositiva. Não é dada ao profissional a possibilidade de optar pela postura ética que ele julga mais adequada para resolver determinado dilema. Se divergir do código, será punido.

Assim, a ética profissional passa a ser, desde sua regulamentação, um conjunto de prescrições de conduta. Deixam, portanto, de ser normas puramente éticas, para serem normas jurídicas de direito administrativo, das quais, do descumprimento de seus mandamentos, decorrem sanções administrativas (advertência; suspensão; dentre outras punições). Nesse contexto, as infrações éticas acabam se equiparando ou sendo tratadas igualmente às demais infrações funcionais. (BITTAR, 2002, p. 368).

Os códigos de profissões regulamentadas por Conselho de Classe são impositivos porque quem os elabora possui autoridade delegada pelo Estado não apenas para criá-los, mas para fazê-los cumprir. Pode-se considerar, como exemplo, a profissão contábil. Ao Conselho Federal de Contabilidade (CFC) foi concedido por delegação do Estado, a partir do Decreto-lei 9295/46, autoridade para punir atos que contrariem as normas de conduta estabelecidas pela classe, quando do exercício profissional, aplicando punições como advertência reservada ou censura pública.
Uma das características comuns desses códigos é o seu caráter coletivo. Os padrões de conduta neles estabelecidos são, de alguma forma, discutidos com os membros que compõem a respectiva classe profissional, gerando regras que devem ser respeitadas por todos. No caso do Código de Ética da Profissão Contábil (CEPC), constituído pela Resolução CFC nº. 803/1996, afirma-se que:

[...] nos últimos 5 (cinco) anos o Conselho Federal de Contabilidade vem colhendo sugestões dos diversos segmentos da comunidade contábil a fim de aprimorar os princípios do Código de Ética Profissional do Contabilista - CEPC. (CFC, 2003, p.78).

Entretanto, embora construídos pela própria comunidade de profissionais, os Códigos de Ética, como o do Conselho Federal de Contabilidade, alcançam os objetivos a que se propõem?

Ainda que a literatura sugira que os Códigos de Ética das organizações empresariais e de entidades profissionais possuam o importante papel de afetar o processo decisório daqueles que estão a ele sujeitos, evidências empíricas indicam que há um reduzido impacto desses códigos ou padrões de conduta no processo decisório. (LERE e GAUMNTZ, 2003, p. 365).

No âmbito empresarial, em estudo a respeito da ética e das relações de trabalho produtivas, observou-se que a conduta moral adotada nas relações de trabalho não expressa elementos presentes no discurso formal da organização contidos em seu código de conduta. O discurso do que se diz não é garantia do que se faz. As justificativas dos gestores às suas ações e atitudes são legitimadas de acordo com a lógica à qual tal organização está subordinada, a saber, a lógica do mercado. (PINTO e FARIA, 2004. p.14). Logo, torna-se cabível questionar se também há diferenças entre o discurso e a prática moral apresentada por uma determinada categoria profissional.

De acordo com Singer (1998, p.14):

Quem quer que já se tenha debruçado sobre uma questão ética difícil sabe muito bem que o fato de nos dizerem o que a sociedade acha que devemos fazer não ajuda ninguém a se resolver por essa ou aquela solução. Precisamos tomar a nossa própria decisão. As crenças e os costumes dentro dos quais fomos criados podem exercer grande influência sobre nós, mas, ao refletirmos sobre eles, podemos agir de acordo com o que nos sugerem, mas também podemos fazer-lhes uma franca oposição.

Nesse contexto, o objetivo deste estudo é investigar a influência do Código de Ética sobre o processo decisório ético do profissional de Contabilidade. Caso o contabilista considere o CEPC como norteador de sua conduta profissional,

1 Conceitualmente, a Ética difere da Moral, mas comumente, no âmbito da ética profissional, são tratadas como sinônimos. 
então é de se esperar que ele procure exercer sua profissão de acordo com os princípios éticos contidos nesse Código e cumpra as demais normas elaboradas pelo órgão fiscalizador de sua profissão. Dessa forma, o código utilizado será um fator importante em seu processo decisório.

A relevância deste estudo decorre do papel desempenhado pelas entidades representativas de profissões regulamentadas sobre a sociedade brasileira, em especial como instrumento de controle social sobre a conduta dos profissionais a elas vinculados.

Na próxima seção, apresenta-se o referencial teórico que abordará diversos modelos voltados para o processo decisório ético do indivíduo. Na seção seguinte, apresentam-se os procedimentos metodológicos adotados. Em seguida, mostram-se os resultados alcançados e, por fim, as conclusões.

\section{REFERENCIAL TEÓRICO}

A tomada de decisão ética corresponde a um processo que abrange a identificação de um problema de natureza ética, a geração de alternativas e a escolha daquela que maximizará os mais importantes valores morais do indivíduo e, ao mesmo tempo, permitirá alcançar o fim pretendido. Implicitamente, nessa definição, está a percepção de que nem todos os valores podem ser maximizados simultaneamente. $\mathrm{O}$ indivíduo deve abdicar de alguns desses princípios para que outros sejam maximizados (GUY, 1990, p. 39).

Os modelos de tomada de decisões éticas na área de negócios visam compreender quais são os determinantes do comportamento ético do indivíduo. Quais os fatores que influenciam a escolha de uma decisão em detrimento das demais. Por esse motivo, eles são amplamente discutidos na literatura internacional. São exemplos os modelos de Rest (1979), Ferrell e Gresham (1985); Hunt e Vitell (1986); Trevino (1986); Ferrell et al. (1989); Ferrell et al. (2001), e Jones (1991). Cada um desses modelos apresenta características próprias que o difere dos demais, seja porque procura sintetizar modelos ou abordar aspectos específicos do indivíduo, não incluídos nos outros.

Como os modelos anteriormente referidos não contemplam claramente os códigos de ética das profissões regulamentadas, optou-se pela utilização do modelo proposto por Alves (2005), representado na Figura $1 \boldsymbol{\theta}$, que incorpora esse aspecto, adaptando os modelos anteriores.

Segundo Alves (2005, p. 111), a obediência do indivíduo ao CEPC não decorre apenas de seu caráter punitivo, se descumprido, mas principalmente da percepção do profissional de que esse conjunto normativo é útil como guia de conduta e reconhecido, de maneira espontânea, como um importante aspecto da atividade profissional.

Entretanto, essa adesão ao Código, por si só, é insuficiente para elucidar como ocorre a tomada de decisão ética. Há de se considerarem os fatores individuais, tais como: o nível de escolaridade do contabilista, bacharel ou técnico em Contabilidade, sua idade, o tempo de registro no Conselho, a religião que professa, entre outras variáveis, as quais ajudam a constituir a sua identidade moral.

É importante destacar que esses fatores têm características que podem influir no posicionamento do profissional em relação aos dilemas éticos que ele enfrenta na sua prática profissional e, conseqüentemente, na sua percepção sobre as normas contidas no Código de Ética.
Por exemplo, um profissional que se reconheça como praticante de uma religião pode aderir ao código por ele conter os mesmos princípios que regem a sua vida religiosa, levando-o a considerar que, por dever profissional e religioso, ele deve utilizá-lo ao se deparar com problemas éticos em seu dia-a-dia.

Nos modelos apresentados neste estudo, exceto no proposto por Jones (1991), os fatores individuais são considerados relevantes, levando os pesquisadores a incluí-los em seus modelos. Contudo, o Código de Ética e os fatores individuais, por si sós, não são as únicas influências no processo de decisão ética do contabilista.

Como outro exemplo, um Contador, profissional assalariado em uma empresa, recebeu determinação da diretoria para postergar o registro de uma despesa vultosa para o mês seguinte ao da elaboração das demonstrações contábeis do exercício em curso. Caso aceite, ele estará superavaliando o lucro do exercício, atendendo, assim, aos interesses da administração, mas agirá em desacordo com as normas contábeis.

Essa situação gera o seguinte dilema: manter o emprego e continuar a sustentar a sua família, ou cumprir o princípio contábil da competência dos exercícios? Portanto, as pressões, que o ambiente organizacional podem impulsionar o contabilista, a descumprir os preceitos do Código de Ética profissional, em benefício de outros interesses.

Essas influências são genericamente denominadas fatores situacionais. Representam forças que geram pressões nos indivíduos e que são capazes de incentivá-los, de encorajá-los ou não à prática moral. Estão incluídas, nessa categoria, as culturas organizacionais, as influências do grupo de trabalho, os valores sociais. Esses fatores compreendem a influência da alta direção, recompensas e punições, e o Código de Ética corporativo.

Assim como nos fatores associados ao agente moral (fatores individuais), os fatores situacionais, igualmente, interferem no julgamento ético dos contabilistas pelos seus pares, compondo parte do cenário em que o profissional de Contabilidade decide o curso de decisões no campo moral.

No que diz respeito à cultura e ao clima organizacionais, por exemplo, segundo Loe et al. (2000, p. 187),

as descobertas nessas áreas sustentam a teoria e as crenças dos gestores de que o gerenciamento da cultura na organização contribui para gerenciar a ética organizacional. 


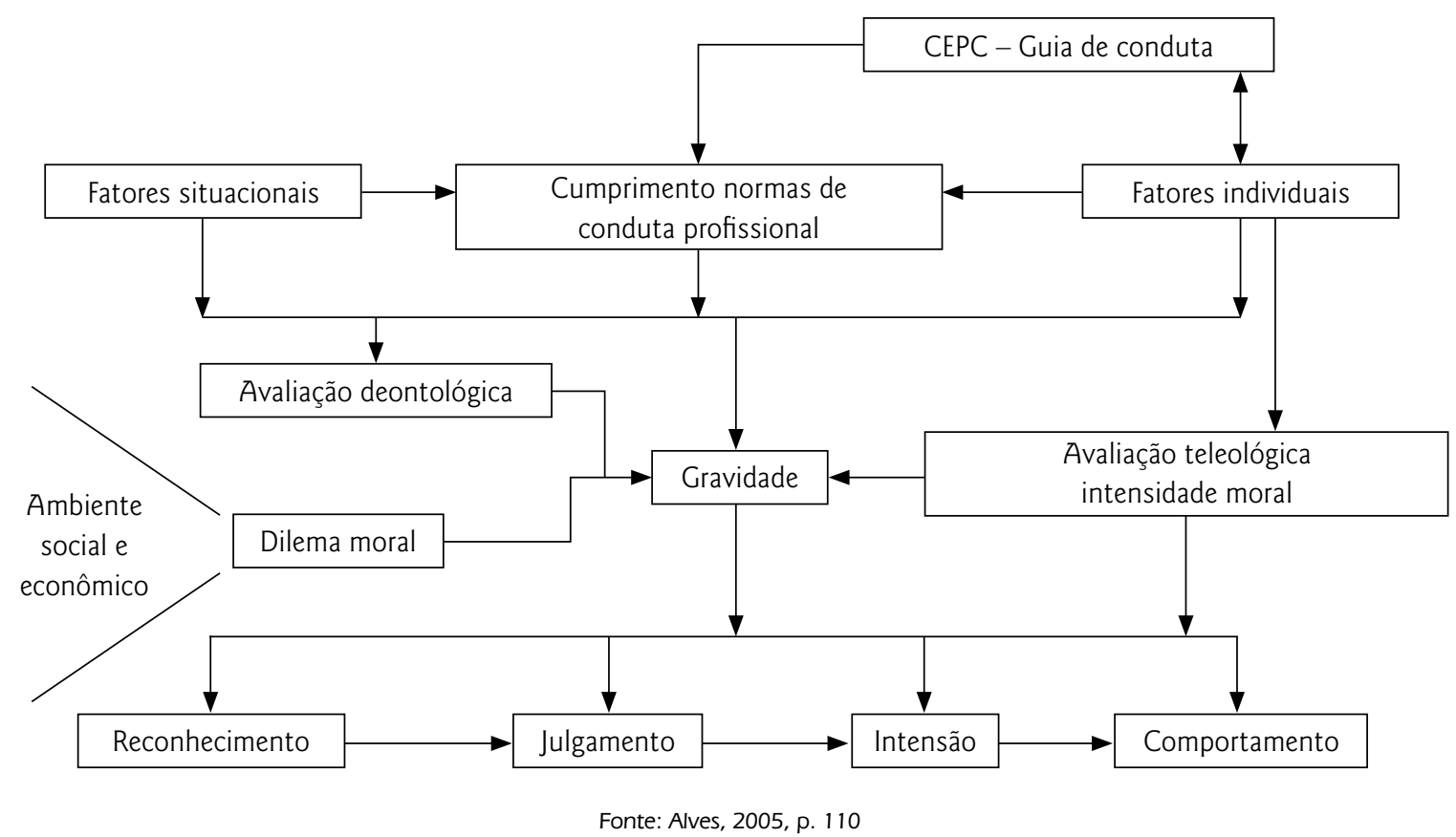

Figura 1 || Modelo de tomada de decisões éticas em Contabilidade

Como interferem na conduta dos profissionais no ambiente das organizações, esses fatores também não podem ser desconsiderados quando se discute o Código de Ética do Contabilista.

A Figura 1 evidencia que os fatores situacionais, o CEPC e os fatores individuais influenciam os quatro componentes psicológicos que determinam o comportamento moral, conforme detalhado a seguir:

a) Componente 1: Consciência de como nossas ações afetam terceiros. Um dilema moral só existirá para determinado indivíduo se ele for capaz de reconhecer a sua existência.

b) Componente 2: Julgamento, por parte do indivíduo, de qual ação é moralmente certa ou errada.

c) Componente 3: Prioridade dada pelo indivíduo a alguns valores morais em detrimento de outros valores (intenção moral). Deficiências nesse componente ocorrem quando o indivíduo não se encontra motivado para pôr os seus valores morais acima de outros interesses.

d) Componente 4: Capacidade do indivíduo para agir de acordo com sua intenção moral. (REST, 1994, p. 23).

Cabe destacar que essas quatro fases foram propostas no modelo criado por Rest, embora o fator cognitivo, pilar do seu modelo, não seja considerado nesta pesquisa como o principal fator que rege a conduta ética dos indivíduos.

As avaliações Deontológica e Teleológica, outros componentes do modelo apresentado na Figura 1, foram propostas originalmente no modelo de Hunt e Vitell (1986, p. 9). Esse modelo, também, é voltado para o ambiente empresarial na área de Marketing, tendo inovado ao conside- rar, de maneira explícita, a importância da filosofia moral, em especial as visões deontológicas e teleológicas sobre o comportamento ético do indivíduo.

$\mathrm{Na}$ avaliação deontológica, o indivíduo analisa a correção, ou não, dos comportamentos que cada alternativa implica. O processo envolve a comparação entre um conjunto de normas deontológicas predeterminadas, princípios universais de comportamento correto e incorreto, representando os valores pessoais ou regras de comportamento. Essas normas variam desde questões que envolvem honestidade, furto e trapaça, até questões mais específicas como o sigilo dos dados, a segurança dos produtos e assim por diante (HUNT; VITELL, 1986, p. 9).

A avaliação teleológica leva o indivíduo a adotar a alternativa que, em sua opinião, trará as melhores conseqüências para ele próprio (Egoísmo ético) ou para as partes envolvidas na questão moral (Utilitarismo ético).

A gravidade do dilema ético corresponde a outro componente desse modelo. Espera-se que ela influa nos juízos de valor do indivíduo nas fases de reconhecimento da questão ética, no julgamento e na intenção de agir. No modelo de Ferrell et al.(2001, p. 94), a gravidade da falta reflete a sensibilidade ética da pessoa em relação a um determinado dilema ético. Neste estudo, essa sensibilidade é formada a partir do conhecimento do profissional a respeito do CEPC, das avaliações deontológica e teleológica, dos fatores individuais e situacionais.

Sob o enfoque dos Códigos de Ética profissionais, a percepção da gravidade da falta também é um fator extremamente importante para a imposição da penalidade a ser aplicada ao infrator, como se observa no capítulo 3, artigo 12, do CEPC, no qual se afirma que a punição deve 
ser aplicada de acordo com a gravidade da falta (CFC, 2003, p. 85).

Dessa forma, o julgamento ético é intrinsecamente relacionado com a percepção de sua gravidade. Por esse motivo, ela foi incluída como um dos componentes essenciais que devem ser observados nesse modelo para fins de aplicação de punição ao infrator.

Ademais, espera-se que a gravidade da falta esteja correlacionada com as variáveis que compõem a intensidade moral. Isso ocorre porque a sensibilidade do indivíduo quanto à gravidade da questão pode aumentar, ou não, dependendo de quem pode ser prejudicado ou beneficiado pela ação (fator teleológico) ou da intensidade com que a questão ética afete terceiros (construto intensidade moral).

De acordo com o modelo de Jones (1991, p.374-378), o construto intensidade moral é composto das seguintes variáveis: a) magnitude das conseqüências. Corresponde à soma dos prejuízos ou benefícios, relacionados ao ato moral em questão, que pode ser gerado para as vítimas (ou beneficiários); b) consenso social. É definido como o grau de concordância social de que um determinado ato é bom ou mau; c ) probabilidade dos efeitos. A intensidade de uma questão moral aumentará, ou diminuirá, dependendo dos malefícios ou benefícios que o indivíduo imagina serem prováveis de ocorrer; d) proximidade temporal. Diz respeito ao tempo decorrido entre o presente e o começo das conseqüências do ato em questão; e) proximidade. Corresponde ao sentimento de proximidade (social, cultural, psicológica ou física) do agente moral em relação às vítimas (ou beneficiários) do ato mau (ou bom) em questão. Pressupõe que as pessoas dão maior atenção àqueles que estão mais próximos em relação àqueles que lhes são mais distantes; f) Concentração de efeitos. A dimensão Concentração dos efeitos é uma função inversa do número de pessoas afetadas por um ato em uma dada magnitude.

Apesar da relevância do construto intensidade moral no modelo proposto por Alves (2005, p. 110), ele não será detalhado nessa revisão bibliográfica, pelo fato de esta pesquisa não envolver análises que o levem em consideração.

Na última etapa do modelo proposto, o comportamento do indivíduo em relação ao dilema ético profissional acresce à sua experiência de vida, permitindo-lhe manter a conduta adotada (ética ou antiética) em situações semeIhantes que possam vir a ocorrer no futuro.

Com base nesse arcabouço conceitual, esta pesquisa busca ampliar o conhecimento a respeito da influência do Código de Ética sobre o processo decisório ético do profissional de contabilidade.

\section{PROCEDIMENTOS METODOLÓGICOS}

A hipótese de pesquisa constituída a partir do seu objetivo, já delineado anteriormente, é: H 1: A percepção do contabilista a respeito da importância do CEPC, como guia de conduta, influencia a sua predisposição em cumpri-lo.

Este estudo é descritivo, pois está estruturado com uma hipótese de pesquisa cujo objetivo é o de averiguar associações entre as diferentes variáveis, e procura descobrir e mensurar as relações de causa e efeito entre elas. (COOPER e SCHINDLER, 2003, p.136).

A sua natureza é quantitativa, pois a amostra deste estudo, com 2034 respondentes, foi coletada por meio de questionários fechados, encaminhados pela Internet a todos os profissionais com registro ativo nos Conselhos Regionais de Contabilidade do Rio de Janeiro, São Paulo, Minas Gerais e Rio Grande do Sul, cujo e-mail seja de conhecimento do respectivo Conselho.

Com o objetivo de permitir a análise dos dados coletados, inicialmente utilizou-se a estatística descritiva seguida da aplicação da técnica de regressão logística multivariada. Ambos os testes foram desenvolvidos por meio do software SPSS,

O Quadro 10 apresenta as definições operacionais das variáveis utilizadas na pesquisa com o objetivo de avaliar o entendimento do contabilista a respeito do CEPC como guia de conduta. Elas apresentam seu valor em uma escala de Likert de 1 a 5 (1- Discordo totalmente; 2- Discordo parcialmente; 3-Indiferente; 4- Concordo parcialmente; 5Concordo totalmente), exceto a variável Q40, expressa em escala ordinal de 1 a 9 .
Em decorrência, as variáveis Q10 e Q13 (questão invertida) e a variável Q40 buscam compreender a importância do CEPC para o profissional de Contabilidade. A variável Q13 foi constituída para avaliar se as respostas dadas à variável Q10, "Importância do CEPC como guia de conduta", ocorreu de forma consistente. Por esse motivo, apresentam sentidos opostos. Se na variável Q10 é dito que "o CEPC é importante", na outra (Q13) afirma-se que "o Código é irrelevante." Assim, espera-se que as respostas assinaladas como "Concordo totalmente" (categoria 5) em uma variável corresponda à opção 1 , na outra variável.

A variável Q14 representa a percepção do respondente quanto à leitura do CEPC, a variável Q15 indica qual o seu nível de clareza, e a variável Q16 evidencia se esse Código é útil para reduzir suas dúvidas no dia-a-dia de sua atividade profissional.

O cumprimento das normas de conduta, variáveis Q11 e Q17, é conceituado, nesta pesquisa, como a disposição do indivíduo de cumprir as normas contidas nesse Código de Ética, Já a Oportunidade, variável Q12, de acordo com Ferrell et al. (2001, p. 101) "descreve as condições que limitam ou permitem um comportamento ético ou antiético do indivíduo" em especial, a percepção do indivíduo de que o CRC não pune os infratores pode favorecer o descumprimento desse Código, conforme Quadro 20.

A variável Q17 - "Cumpro todas as normas elaboradas pelo Conselho Federal de Contabilidade", mesmo que discorde de algumas ou de todas, foi originalmente constituída segundo a escala de Likert com cinco categorias e, a 


\begin{tabular}{|c|l|c|c|}
\hline No & \multicolumn{1}{|c|}{ Definição } & Valor & Classificação \\
\hline Q10 & Importância do CEPC como guia de conduta para o profissional & Escala de Likert & Ordinal \\
\hline Q13 & Irrelevância do CEPC para a atividade profissional (Questão reversa) & Escala de Likert & Ordinal \\
\hline Q14 & Nível de conhecimento (leitura) sobre o CEPC & Escala de Likert & Ordinal \\
\hline Q15 & Nível de clareza do CEPC & Escala de Likert & Ordinal \\
\hline Q16 & Auxílio do CEPC para reduzir dúvidas do profissional & Escala de Likert & Ordinal \\
\hline Q40 & Nota dada ao CEPC & Nota de 1 a 9 & Ordinal \\
\hline
\end{tabular}

Quadro 1 Variáveis que compõem o CEPC como guia de conduta

\begin{tabular}{|c|l|l|c|}
\hline № & \multicolumn{1}{|c|}{ Definição } & \multicolumn{1}{|c}{ Valor } & \multicolumn{1}{|c|}{ Classificação } \\
\hline Q11 & Cumprimento das normas (Questão reversa) & Escala de Likert - invertida & Ordinal \\
\hline Q17 & Cumprimento de norma & Escala de Likert & Ordinal \\
\hline Q17bin & $\begin{array}{l}\text { Cumprimento de norma. Corresponde à variável } \\
\text { Q17 em forma binária }\end{array}$ & $\begin{array}{l}\text { 0- Não cumpro totalmente as normas do CFC } \\
\text { 1- Cumpro totalmente as normas do CFC }\end{array}$ & Ordinal \\
\hline Q12 & O CRC pune as infrações ao Código de Ética & Escala de Likert & Ordinal \\
\hline
\end{tabular}

Quadro 2 |Variáveis que compõem o cumprimento de normas de conduta e a oportunidade

seguir, reduzida para duas escolhas: ou ele cumpre, ou ele não cumpre o CEPC. Em essência, portanto, é uma variável dicotômica.

As variáveis Q11 e Q17, também, apresentam seu valor em uma escala de Likert de 1 a 5 (1- Discordo totalmente; 2- Discordo parcialmente; 3- Indiferente; 4- Concordo parcialmente; 5- Concordo totalmente). A variável Q11 encontra-se na forma invertida (negativa) com o intuito de avaliar a consistência das respostas dadas para a variável Q17.

$\mathrm{O}$ uso da escala de Likert com 5 categorias e a posterior transformação para dicotômica deveu-se à ponderação feita por Aaker et al. (2001, p. 324):

as perguntas sobre atitudes invariavelmente possuem posições intermediárias. [...] como regra geral, o espectro de opiniões pode ser mais bem capturado, na maioria dos casos, com cinco a sete categorias de respostas.

Em decorrência, optou-se, inicialmente, por considerar uma amplitude maior de respostas, para que a categoria
"Concordo totalmente" contenha um nível de consistência maior do que se simplesmente houvesse as opções "Cumpro" ou "Não cumpro o CEPC." No decorrer das análises dos dados, essa variável (Q17) foi reclassificada como dicotômica (Q17bin), com o valor 0 (zero) para as respostas assinaladas nas categorias "1- Discordo totalmente" até "4- Concordo parcialmente." A opção 1 ficou restrita às afirmações assinaladas como "5- Concordo totalmente" na escala original de Likert.

Como a hipótese de pesquisa visa à descoberta de associações entre diferentes variáveis, e considerando que a variável dependente (Q17bin) é dicotômica, optou-se pela técnica de regressão logística multivariada a qual permite que se tenha, segundo Hair (2005, p. 129),

[...] não apenas maior capacidade de previsão, mas também uma explicação aprimorada da relação da variável dependente com as variáveis independentes.

\section{ANÁLISE DOS RESULTADOS}

A amostra foi composta por 2262 respondentes, sendo 1546 Contadores, 698 Técnicos em Contabilidade, e 18 indivíduos que não se identificaram. Todos os profissionais pesquisados possuem registro ativo em Conselho Regional de Contabilidade.

A Tabela $1 \bullet$ traz as freqüências de todas as variáveis relacionadas ao questionário. Foi estabelecido o seguinte código para as opções de resposta: 1 - Discordo totalmente; 2- Discordo parcialmente; 3-Indiferente; 4- Concordo parcialmente; e 5 - Concordo totalmente.

É possível observar que os dados válidos e os dados faltantes praticamente não sofreram alterações. Isso ocorreu porque o respondente só avançou nas páginas do ques- tionário apresentadas na Internet, após ter respondido a todas as questões de uma página. A tabela mostra que 228 respondentes abandonaram o questionário nesse momento.

A Tabela 1 evidencia que há uma tendência de os respondentes concordarem totalmente com a afirmação (Q10) de que o CEPC é importante para guiar a conduta profissional do contabilista $(72,86 \%)$, bem como de discordarem totalmente $(56,59 \%)$ da afirmação de que o CEPC é irrelevante para o profissional como guia de conduta (Q13).

Cerca de $80 \%$ dos respondentes concordaram total ou parcialmente que o CRC pune os infratores do Código (Q12). Esse percentual elevado tende a evidenciar a 
Tabela 1 Freqüências das questões vinculadas ao CEPC

\begin{tabular}{|c|c|c|c|c|c|c|c|}
\hline \multirow[t]{2}{*}{ CEPC como guia de conduta } & \multirow[t]{2}{*}{$\begin{array}{l}\text { Dados } \\
\text { válidos }\end{array}$} & \multirow[t]{2}{*}{$\begin{array}{c}\text { Dados } \\
\text { faltantes }\end{array}$} & \multicolumn{5}{|c|}{$\begin{array}{l}\text { Opções de respostas } \\
\text { Freqüência }\end{array}$} \\
\hline & & & 1 & 2 & 3 & 4 & 5 \\
\hline Q10 - Importância do CEPC como guia de conduta & 2034 & 228 & 31 & 28 & 108 & 385 & 1482 \\
\hline Q13 - Irrelevância do CEPC como guia de conduta (reversa) & 2034 & 228 & 1151 & 261 & 137 & 223 & 262 \\
\hline Q15 - Nível de clareza do CEPC & 2034 & 228 & 62 & 204 & 188 & 941 & 639 \\
\hline Q16 - Auxílio do CEPC para reduzir as dúvidas profissionais & 2034 & 228 & 85 & 161 & 293 & 867 & 628 \\
\hline Q14 - Nível de conhecimento & 2034 & 228 & 109 & 90 & 126 & 480 & 1229 \\
\hline Oportunidade & & & & & & & \\
\hline Q12 - Restrições situacionais & 2034 & 228 & 81 & 183 & 129 & 605 & 1036 \\
\hline Normativo & & & & & & & \\
\hline Q11 - Cumprimento de normas (reversa) & 2034 & 228 & 743 & 319 & 47 & 641 & 284 \\
\hline Q17 - Cumprimento de norma & 2034 & 228 & 61 & 125 & 192 & 752 & 904 \\
\hline
\end{tabular}

percepção do respondente quanto à ação fiscalizadora do CRC, sem, contudo, apontar o rigor dessa punição.

Quanto à clareza das disposições contidas no CEPC (Q15) e ao auxílio que ele presta no esclarecimento de dúvidas, no dia-a-dia do profissional (Q16), os percentuais dos que não concordam total ou parcialmente com essas afirmações são de $68,6 \%$ e 69,1\%, respectivamente.

As questões Q17 e a Q11 (questão reversa), ambas vinculadas ao caráter normativo do CEPC, apresentam uma tendência semelhante às variáveis Q10 e Q13. No total, 904 respondentes $(44,4 \%)$ concordaram totalmente que cumprem as normas elaboradas pelo CEPC, enquanto na questão reversa (Q11) há a discordância total ou parcial quanto à irrelevância do CEPC, de 1062 profissionais, $51,2 \%$ dos dados válidos.

$\mathrm{Na}$ questão Q40, solicitou-se ao respondente que atribuísse uma nota ao Código de Ética. Os resultados encontram-se na Tabela $2 \mathbf{O}$.

A questão foi respondida por 1785 profissionais. A nota média dada à importância do CEPC como guia de conduta é 8 , sendo 9 o ponto mediano. Isso significa que os respondentes julgaram o Código de Ética muito importante para o exercício de suas atividades profissionais diárias.

A análise exploratória dos dados possibilitou uma visão abrangente das afirmações feitas pelos respondentes. $\mathrm{Na}$ etapa seguinte, foi aplicada a técnica de regressão logística multivariada visando à descoberta de associações entre diferentes variáveis.

Na Tabela 30 é apresentado o resumo das respostas dadas à questão Q17 - "Cumprimento total das normas do CFC" necessárias para se comprovar, ou refutar, a Hipótese 1 desta pesquisa.

A Tabela 3 mostra que foram incluídas na análise 1785 respostas que, acrescidas dos casos faltantes, totalizam 2262 indivíduos que responderam à pesquisa total ou parcialmente.

A variável dependente Q17 - "Cumpro todas as normas elaboradas pelo Conselho Federal de Contabilidade, mesmo que discorde de algumas ou de todas", foi reclassificada de uma escala de 5 itens - "Discordo totalmente" a "Concordo totalmente", para uma escala dicotômica

Tabela 2 Nota sobre o grau de importância do Código de Ética nas atividades do contabilista

\begin{tabular}{|c|c|c|c|c|c|}
\hline Dados válidos & Dados faltantes & Média & Mediana & Moda & Desvio-padrão \\
\hline 1785 & 477 & 8 & 9 & 9 & 1,65 \\
\hline
\end{tabular}

Tabela 3 || Resumo dos casos processados

\begin{tabular}{l|c|c|c}
\multicolumn{1}{c|}{ Casos sem pesos } & & № & Percentual \\
Casos selecionados & Incluídos na análise & 1785 & 78,9 \\
\hline & Dados faltantes & 477 & 21,1 \\
\hline Casos não selecionados & Total & 2262 & 100,0 \\
\hline Total & & 0 & 0,0 \\
\hline
\end{tabular}


1- "Concordo totalmente em seguir o CEPC" e 0 - "Não concordo totalmente em seguir o CEPC".

Dessa forma, os contabilistas que responderam às opções 1, 2, 3 ou 4 (Discordo totalmente até Concordo parcialmente) para a variável Q17 foram codificados como 0 e os que responderam que concordam totalmente (5) obtiveram o código 1.

As variáveis independentes, utilizadas nesse modelo, foram todas relacionadas ao CEPC como guia de conduta (Q10 e Q11, Q13 a Q16 e Q40) e a Q12 vinculada aos Fatores situacionais.

Antes de calcular a regressão logística, o SPSS apresenta uma tabela de classificação inicial das respostas, a qual contém as estimativas para o modelo nulo com apenas uma constante, conforme pode ser observado na Tabela $4 \mathbf{0}$. Nesse caso, com a categoria "0- não cumpro", o modelo será capaz de predizer com 100\% de correção essa opção. Em contrapartida, o modelo errará toda a estimativa para a categoria "1 - Não cumpro". Como resultado final, o modelo nulo é capaz de predizer com correção 55\% (992/1785) de todas as respostas válidas. Espera-se que, após a inclusão das variáveis independentes no modelo, a sua capacidade de previsão ultrapasse $55,5 \%$.

O método de regressão logística adotado para avaliar a Hipótese 1 de pesquisa, por meio do uso do software SPSS, foi o de entrada. Com esse método, todas as variáveis são incluídas no modelo, sejam significativas ou não. Assim, foi possível avaliar o impacto conjunto das variáveis Q10 a Q16 e a Q40 na variável dependente Q17 (Cumprimento total do (EPC).

A primeira avaliação do ajuste geral do modelo, utilizando o método de entrada, é feita pela análise do valor do logaritmo da verossimilhança $(-2 \mathrm{LL})$ por meio dos testes de Omnibus dos coeficientes do modelo. De acordo com Hair
(2005, p. 264), "valores menores da medida -2LL indicam melhor ajuste do modelo".

Nesta pesquisa, o valor alcançado foi 1.962,13, estatisticamente significativa (valor $p<0,05$ ). Em seguida, o SPSS demonstra o $\mathrm{R}^{2}$, de acordo com os testes de Cox e Snell, bem como de Nagelkerke. Esse teste visa a demonstrar a força de associação entre as variáveis do modelo. Valores mais altos para os testes de Cox e Snell indicam melhor ajuste do modelo, enquanto para o teste de $\mathrm{Na}$ gelkerke, quanto mais próximo o valor alcançado se aproxime de 1, melhor será o ajuste (HAIR, 2005, p. 264).

Como se observa na Tabela $5 \mathbf{0}$, o $\mathrm{R}^{2}$, para ambos os testes, tem uma fraca força de associação entre as variáveis. Contudo, Gujarati (2000, p.566), afirma que

[...] em modelos com variável dependente dico-

tômica, o $R^{2}$ é de valor questionável como medida do

grau de ajuste.

Por esse motivo, sua análise não foi considerada para fins de validação do modelo.

$\mathrm{O}$ teste de Hosmer Lemeshow corresponde à segunda avaliação geral do modelo. Esse teste mede a correspondência entre os valores reais e os valores previstos da variável dependente. Um melhor ajuste de modelo é apontado por uma menor diferença entre a classificação observada $e$ a classificação prevista, e indicado por um valor qui-quadrado não-significante. Esse ajuste mede a correspondência entre os valores atuais e os preditos da variável dependente. (HAIR et al., 2005, p. 264).

O teste de Hosmer e Lemeshow (Tabela $6 \mathbf{0}$ ) apresentou significância estatística adequada (valor $p>0,05$ ). Isso mostra que as diferenças entre os valores observados e os valores previstos são poucas. A combinação do teste de Hosmer e Lemeshow (valor $p>0,05$ ) e de Omnibus (va-

Tabela 4 Classificação inicial das respostas do cumprimento de normas

\begin{tabular}{c|c|c|c|c}
\multirow{2}{*}{ Observado } & \multicolumn{3}{c}{ Predito } \\
\cline { 3 - 5 } & & \multicolumn{2}{c}{ Q17BIN } & Percentagem \\
\cline { 3 - 5 } & & 0- Não cumpro & 1- Cumpro & correta \\
\hline \multirow{2}{*}{ Q17BIN } & 0- Não cumpro & 992 & 0 & 100,0 \\
\hline & 1- Cumpro & 793 & 0 & 0,0 \\
\hline Total & & 1785 & & 55,5
\end{tabular}

Tabela 5 - Teste do $R^{2}$

\begin{tabular}{|c|c|c|}
\hline Passo & Cox \& Snell & Nagelkerke \\
\hline 1 & 0,240 & 0,322 \\
\hline
\end{tabular}

Tabela 6 Teste de Hosmer and Lemeshow

\begin{tabular}{|c|c|c|c|}
\hline Passo & Qui-quadrado & Desvio-padrão & Significância \\
\hline 1 & 10,150 & 8 & 0,255 \\
\hline
\end{tabular}


lor $p<0,05)$ ocorreu nesta pesquisa. Isso demonstrou que o modelo de regressão logística é significativo e adequado para o exame de suas variáveis.

A classificação das respostas seguiu o ponto de corte de 0,45. Abaixo desse valor os indivíduos foram considerados como "Não cumpro" e acima desse ponto como "Cumpro." Os resultados são apresentados na Tabela $7 \mathbf{0}$

A Tabela 7 mostra que, dos 793 respondentes que concordaram em seguir o CEPC, o modelo conseguiu predizer, com $69,5 \%$ de acerto (551 respondentes), que essa seria a sua opção. Por outro lado, o modelo, também, previu, com $72,3 \%$ de acerto, que o respondente não concorda em cumprir as normas do CEPC.

Esse padrão de acertos demonstra que, em média, as variáveis independentes permitem predizer uma parte considerável das respostas possíveis na variável dependente
(71\%). Há, porém, outras variáveis que devem influenciar o profissional em sua decisão (29\%), mas essas não foram relacionadas neste modelo.

É importante destacar que, se houver associação positiva entre as variáveis (ou categorias) independentes e a variável dependente, opção 1 (um), "Concordo totalmente em cumprir as normas do CEPC", naturalmente, a associação entre essas mesmas variáveis independentes e a variável dependente, opção 0 (zero), "Discordo em cumprir totalmente as normas do CEPC" será negativa. Quanto maior a probabilidade de ocorrência da opção 1, menor será a probabilidade de ocorrer a opção 0.

Uma vez aplicada a regressão logística multivariada para todas as variáveis que compõem o modelo, constituiu-se a seguinte equação:

$$
\begin{gathered}
Z=-5,395+0,110 Q 10(2)+0,575 Q 10(3)+0,115 Q 10(4)+0,392 Q 10(5)-0,623 Q 11(2) \\
-1,784 Q 11(3)-0,737 Q 11(4)+0,019 Q 11(5)-0,181 Q 12(2)-0,014 Q 12(3)+0,097 Q 12(4) \\
+0,426 Q 12(5)-0,435 Q 13(2)+0,239 Q 13(3)-0,448 Q 13(4)-0,152 Q 13(5)-0,420 Q 14(2) \\
+0,177 Q 14(3)+0,670 Q 14(4)+1,039 Q 14(5)-0,593 Q 15(2)-0,868 Q 15(3)-1,075 Q 15(4) \\
-0,504 Q 15(5)+0,274 Q 16(2)+0,465 Q 16(3)+0,431 Q 16(4)+1,295 Q 16(5)+3,785 Q 40(1) \\
+3,326 Q 40(2)+3,638 Q 40(3)+2,379 Q 40(4)+3,695 Q 40(5)+3,665 Q 40(6)+3,891 Q 40(7) \\
+4,027 Q 40(8)+4,680 Q 40(9)
\end{gathered}
$$

A probabilidade de ocorrência do evento será: $P=e^{z} /$ $\left(1+e^{z}\right)$. O valor de corte foi de 0,45 , se $P>=0,45$, então, o indivíduo é classificado como um profissional que se dispõe a seguir o CEPC; caso contrário, isto é, se $\mathrm{P}<0,45$, ele será classificado como "Não cumpre."

Nesse modelo, foram incluídas todas as variáveis independentes relacionadas com as diferentes percepções do contabilista a respeito do CEPC e a variável que representa os fatores individuais (Q12). Por meio do método de entrada, foi possível apurar quais variáveis independentes efetivamente influem, de maneira significativa, na propensão do indivíduo em cumprir, ou não, o CEPC. São elas: Q11, Q12, Q13, Q14, Q15, Q16, e Q40.
Todas as variáveis incluídas no modelo alcançaram significância estatística (valor $p<0,05$ ), exceto a variável Q10, que apresentou significância de 0,359. A variável Q40, embora significativa não apresentou significância estatística entre as categorias que a compõem.

$A$ afirmação de que se deve cumprir somente aquelas normas elaboradas pelo CFC que são julgadas corretas (Q11), por ser uma questão significativa e reversa, corro-

\begin{tabular}{|c|c|c|c|c|c|c|}
\hline & & & \multicolumn{4}{|c|}{ Predito } \\
\hline \multicolumn{3}{|c|}{ Observado } & \multicolumn{2}{|l|}{ Q17 } & \multirow{3}{*}{$\begin{array}{c}\text { Percentagem } \\
\text { correta } \\
72,3\end{array}$} & \multirow{3}{*}{$\begin{array}{r}\text { Total } \\
992\end{array}$} \\
\hline & & & Concordo totalmente & Discordo & & \\
\hline \multirow[t]{3}{*}{ Passo 1} & Q17 & Não cumpro & 717 & 275 & & \\
\hline & & Cumpro & 242 & 551 & 69,5 & 793 \\
\hline & Total & & & & 71,0 & 1785 \\
\hline
\end{tabular}
borou a afirmação contida na variável dependente Q17.

A percepção de que o CRC pune quem infringe o CEPC (Q12) apresentou alta significância (valor $p<0,05$ ). Entretanto, foi identificado que a sua significância estatística não foi mantida para as duas subamostras criadas

Tabela 7 Classificação das respostas ao cumprimento do CEPC - final 
para validar esse modelo. Sendo assim, essa variável não foi validada.

A afirmação a respeito da irrelevância do CEPC como guia de conduta (Q13), questão reversa em relação à $\mathrm{Q}(10)$, foi considerada significativa (valor $p<0,05$ ), e as categorias "Discordo parcialmente", Q13(2), e "Concordo parcialmente", Q13(4), também foram consideradas significativas (valor $p<0,05$ ). Entretanto, como possuem sinais negativos, isso sugere que as assinalar reduz a razão de chance de o indivíduo cumprir as normas do CEPC, em relação aos que assinalaram a categoria "Discordo totalmente", Q13(1).

A percepção do respondente quanto ao seu nível de conhecimento a respeito do CEPC (Q14) foi considerada significativa (valor $p<0,05$ ). Os indivíduos que concordaram parcialmente com essa afirmação apresentaram razão de chance de 1,95 de cumprir as normas do CEPC, bem como os que concordaram totalmente têm 2,82 mais chances de cumpri-lo em relação aos que afirmaram que não o leram.

Se a variável Q14 influencia a percepção do contabilista quanto ao cumprimento do CEPC em relação aos que não o leram, é cabível concluir que a ampla divulgação e discussão pelos profissionais, por meio de seminários, palestras, artigos em periódicos, e assim por diante, deve ser incentivada. Essa ação deve ser feita com a mesma ênfase com que hoje se discutem mudanças na legislação societária e fiscal.

Em relação à afirmação Q(15) "As normas do Código de Ética são claras e não deixam dúvida quanto ao seu sentido", constatou-se que as categorias "Indiferente" Q15(3), e "Concordo parcialmente" foram significativas (valor $p<$ $0,055)$, bem como a própria variável. Entretanto, por apresentarem sinais negativos, a escolha de uma dessas opções demonstra que o indivíduo está propenso a descumprir as normas do CEPC.

Caso o indivíduo concorde, totalmente com a afirmação de que o CEPC é um auxílio importante para reduzir as suas dúvidas profissionais (Q16), há 3,65 mais chances de ele cumprir o referido Código, comparado àqueles que discordaram totalmente dessa afirmação. Esse resultado permite aceitar a Hipótese 1 de pesquisa: a percepção do contabilista a respeito da importância do CEPC, como guia de conduta, influencia a sua predisposição de cumprir o Código de Ética.

\section{CONCLUSÕES}

Este estudo demonstrou que $73 \%$ dos profissionais estão totalmente de acordo com a afirmação de que o CEPC é importante como guia de conduta. Entretanto, apenas $44,4 \%$ dos respondentes concordaram totalmente com a afirmação de que o profissional deve cumprir as normas elaboradas pelo CFC mesmo que discorde de algumas dessas normas. Outro fato relevante é que apenas $31,42 \%$ dos respondentes concordaram totalmente com a afirmação de que o CEPC é claro em suas normas.

Os resultados obtidos evidenciam uma contradição: mostram que nem todos os profissionais que concordaram totalmente com a afirmação de que o CEPC é importante como guia de conduta, se predispõem a seguí-lo. Se há pouca propensão em cumprir o CEPC, é inequívoco que muitos profissionais, ao se verem envolvidos em dilemas morais em sua atividade profissional, estarão mais propensos a decidir qual é a melhor atitude a tomar, do ponto de vista ético, por outros parâmetros, que não os professados pela categoria. Assim, esta pesquisa sugere que há a mesma contradição entre discurso e prática moral já percebida em estudos empíricos anteriores.

Com a utilização da regressão logística multivariada foram evidenciados alguns aspectos que podem contribuir para a propensão do profissional em cumprir as normas estabelecidas em sua classe profissional, conforme apresentado a seguir:

a) Se os profissionais concordarem totalmente com a afirmação de que já leram o CEPC (Q14), então eles apresentam 2,82 mais chances de cumprir as suas determinações do que aqueles que discordaram dessa afirmação. Por conseguinte, a leitura do
Código atua positivamente sobre o profissional, aumentando a sua predisposição de cumpri-lo. Portanto, a leitura do Código deve ser incentivada.

b) Se o profissional concordar totalmente com a afirmação de que o CEPC o ajuda a reduzir as suas dúvidas profissionais (Q16), há 3,65 mais chances de ele cumprir o Código, em comparação com os que discordam totalmente dessa afirmação.

Os resultados sugerem que há associação entre a variável dependente cumprimento das normas (Q17) e as variáveis que representam a importância do CEPC como guia de conduta (Q11, Q13 a Q16 e Q40). Em conseqüência, aceita-se a Hipótese 1 de pesquisa: a percepção do contabilista a respeito da importância do CEPC como guia de conduta influencia a sua predisposição de cumprir o Código de Ética.

Em síntese, se o Código de Ética profissional é percebido pelo indivíduo como guia de conduta, ele estará mais propenso a cumprir as normas emanadas do CFC, reduzindo, dessa forma, a possibilidade de ocorrência de ações que prejudiquem os diversos usuários das informações contábeis. Além dessa predisposição para acatar as normas do Código de Ética, fatores como religião, o nível de escolaridade, a cultura organizacional, dentre outros, podem influenciar o processo decisório ético do indivíduo.

Nesse sentido, considerando-se que pesquisas como essa, que envolvem as diferentes percepções dos indivíduos no campo do processo decisório ético, têm em comum o fato de não serem conclusivas nem exaustivas, há a necessidade de serem investigados os efeitos de outras 
variáveis individuais, como a influência da idade, experiência profissional ou gênero no processo decisório ético do indivíduo.

Também é importante ampliar o conhecimento a respeito da influência dos fatores relacionados ao ambiente em que o indivíduo atua, tais como a cultura organizacional, os colegas de trabalho, as premiações e as sanções impostas pela organização ou pelo Conselho Profissional no qual o indivíduo está inscrito.

Espera-se que este estudo incentive pesquisadores a que busquem maior compreensão das peculiaridades do comportamento moral e respectivo processo decisório, desses e de outros profissionais, ampliando assim, a discussão de um tema de extrema relevância em nossa sociedade.

\section{Referências Bibliográficas}

AAKER, David A.; et al. Pesquisa de Marketing. São Paulo: Atlas. 2001.

ALVES, Francisco José dos Santos. Adesão do Contabilista ao Código de Ética da sua profissão: um estudo empírico sobre percepções. 2005. Tese (Doutorado em Controladoria e Contabilidade). Faculdade de Economia, Administração e Contabilidade. Universidade de São Paulo, São Paulo.

BITTAR, Eduardo C.B.. Curso de Ética Jurídica: ética geral e profissional. São Paulo: Saraiva, 2002.

CONSELHO FEDERAL DE CONTABILIDADE - CFC. Legislação da profissão contábil. Brasília, 2003.

COOPER, Donald R.; SCHINDLER, Pámela S.. Métodos de Pesquisa em Administração. 7 ed.. Porto Alegre: Bookman, 2003.

FERRELL, O. C.; GRESHAM, LG. A contingency framework for understanding ethical decision making in marketing. Journal of marketing. Chicago: American Marketing Association, v. 49, Summer, 1985.

; et al. A synthesis of ethical decision models for Marketing. Journal of Macromarketing. London: Sage Publications, n. 55, v. 9, 1989.

; et al. Ética Empresarial: dilemas, tomadas de decisões e casos. 4 ed.. Rio de Janeiro: Reichmann \& Affonso Editores, 2001.

GUJARATI, Damondar. Econometria Básica. 3 ed.. São Paulo: Makron Books. 2000.

GUY, Mary E.. Ethical Decision Making in Everyday Work Situations. Quorum Books. Westport, CT. 1990.

HAIR, Joseph F.; et. al. Análise Multivariada de Dados. Porto Alegre: Bookman. 2005.

HUNT, D. S.; VITELL, S.. A general theory of Marketing Ethics. Jornal of Macromarketing. London: Sage Publications, v. 6, n. 1, p. 9-16, 1986.

JONES, Thomas M.. Ethical decision making by individuals in organizations: an issue-contingent model. The Academy of Management Review. New York: Academy of Management, v. 16, Iss 2, p. 266-395, Apr. 1991.

LERE, John, C.; GAUMNTZ, R.. The impact of Codes of Ethics on decision making: Some insights from information economics. Journal of Business Ethics. Dordrecht. Vol. 48, Iss. 4, p. 365. dec. 2003.

LOE, Terry W.; et al. A review of empirical studies assessing ethical decision making in business. Journal of Business Ethics. Kluwer Academic Publishers, v. 25, p. 185-205, 2000.

PINTO, Rodrigo Serpa; FARIA, José Henrique. O Discurso e a Prática da Ética nas Relações de Trabalho: os Paradoxos da Práxis de uma Organização Bancária. Anais do ENANPAD. 2004, p. 16.

REST, J. R.. Development in judging moral issues. Minneapolis: University of Minnesota Press. 1979.

; NARVÁEZ, Darcia. Moral Development in the Professions: Psychology and Applied Ethics. Lawrence Erlbaum Associates. Hillsdale, NJ. 1994. p. 22.

SARBANES-OXLEY Act of. Senate and House of Representatives of the United States of América. Sarbanes-Oxley Act of 2002 Washington. Disponível em $<$ http://findlaw.com $>$. Acesso em: 2003.

SINGER, Peter. Ética prática. São Paulo: Martins Fontes, 1998.

TREVINO, Linda K.. Ethical decision making in organizations: a person-situation interactionist model. The Academy of Management Review. Vol. 11, n. 3, p. 601-617, 1986.

\section{NOTA - Endereço dos autores}

Universidade do Estado do Rio de Janeiro

Campus Francisco Negrão de Lima

R. São Francisco Xavier, 524 - $9^{\circ}$ andar - Bloco E

Rio de Janeiro - RJ

20550-900

Universidade de São Paulo

FEA - Departamento de Contabilidade e Atuária

Av. Prof. Luciano Gualberto, 908 - prédio 3

São Paulo - SP

05508-900
Fundação Escola de Comércio Álvares Penteado

Av. Liberdade, 532 - Liberdade

São Paulo-SP

01502-001

Universidade Presbiteriana Mackenzie

Centro de Ciências Sociais e Aplicadas

Rua da Consolação, 930 - Consolação

São Paulo - SP

01302-090 